\title{
A Wind Turbine System Model using a Doubly-Fed Induction Generator (DFIG)
}

\author{
Amevi Acakpovi \\ Accra Polytechnic -Ghana \\ P.O. Box: GP561
}

\author{
Essel Ben Hagan \\ Accra Institute of Technology - Ghana \\ P.O. Box AN-19782, Accra-North
}

\begin{abstract}
The ever growing interest in developing green energy worldwide has led to the development of hybrid energy system. Many hybrid energy systems do involve wind systems due to the availability and easy access of wind resource. This paper works on the development and the simulation of a wind farm adaptable to high voltage transmission network. It also implements a control of pitch angle using a PID controller, in order to stabilize rotor speed. Firstly a comprehensive analytical model of wind turbine has been presented and this was followed by the modeling of the wind farm under SimPowerSystem of Simulink. The simulated wind turbine system uses a Doubly Fed Induction Generator (DFIG) having a capacity of six (6) MW that supplies a distribution system at $33 \mathrm{KV}$. A load is connected at the end of the distribution network through a $20 \mathrm{~km}, 33 \mathrm{KV}$ feeder. PID control system has been implemented to regulate the speed of the rotor vis-àvis the wind speed variations. Results show that the speed regulation was very good. In permanent regime, the variation of rotor speed was almost insignificant despite the continuous variation of the wind speed within the interval of 12 to $15 \mathrm{~m} / \mathrm{s}$. At the same time, the active and reactive power obtained were in agreement with the simulation pre-set values.
\end{abstract}

\section{General Terms}

Modeling, Simulation, Wind Turbine, Wind Farm, Speed Control, pitch angle

\section{Keywords}

Power coefficient, DFIG, PID controller, Rotor Speed, Generated Voltage and Current.

\section{INTRODUCTION}

Manwell \& al. (2002), [1], described wind energy as the mechanism by which, blowing wind can be captured and converted into mechanical energy or electricity. In fact, blowing wind possesses kinetic energy which can be converted into mechanical energy by wind turbines. The mechanical power produced can be used for special tasks including powering homes, businesses and other appliances. Wind energy has recently gained interest worldwide and this has led to the development of various models of wind generation system under different software.

A wind turbine generation system (WTGS) generally comprises of a wind turbine, an electric generator and various control systems. Commonly encountered wind generators installed at present include squirrel cage induction generator, wound field synchronous generator, doubly fed induction generator, and permanent magnet synchronous generator [2]. Wind turbine models are also classified as variable or fixe speed wind turbine based upon their rotational speed [2], [3].

However, modeling a WTGS is a complex task involving the modelling of the turbine, the generator and the power converter which ensures that the frequency of the supply voltage is in conformity with the transmission system because the originally generated voltage by the WTGS is never compliant to the grid. In addition, control mechanism must be added to regulate the rotor speed which is directly related to the wind speed variations. Matlab/SimPowersytem has inbuilt systems encompassing all the various aspect of wind modeling described above, with the purpose of simplifying the modeling tasks.

The main objective of this paper is to design a flexible model of wind farm including all the aspects described above. The model would later serve to build a hybrid energy systems in combination with other renewable energy models.

\section{PREVIOUS WORKS}

Several techniques have been used in the past to model wind systems for power generation. Most available models are analytical while others are computer based. Hansen \& al. (2003), [3], provided a comprehensive report on the modelling of wind turbine at both system and component level using the DIgSILENT software. Their work dealt with the description of DIgSILENT built-in models of electrical components used for wind turbine system comprising: an induction generator, a power converter and other models developed by user in the dynamic simulation language (DSL) of DIgSILENT [3]. Also, models of non-electrical components of wind turbine system such as wind speed model, aerodynamic model and others, were equally made available.

In addition, Bolik (2004), [4] developed a computer model of wind turbine that has been widely used by power-system operators to study load flow, steady state, voltage stability, dynamic and transient behaviour of power system. This system was also simulated with DigSILENT. DigSILENT has the capability to simulate load flow, RMS fluctuations and transient events [4]. It provides models on different levels and can also be used to simulate load flow, RMS fluctuation and transient events in the same environment.

Besides [3] and [4], Fingersh \& al. (2006), [5] developed under The National Renewable Energy Laboratory (NREL), an agency of US, a wind turbine model intended to provide reliable cost projections for wind-generated electricity based on different scales (sizes) of turbines. The model was mainly analytical. Petru (2001), [6] has also developed a similar analytical model of wind turbine as a project work and this was well elaborated on other aspects of wind system such as the aerodynamic modeling, the wind data modeling, the mechanical aspect....

Moreover, Sulla (2009), [7] modeled and simulated a doubly fed Induction Generator and the fixe speed Induction generator with MATLAB Simpowersystem toolbox. The system was made of a graphical model built under Simulink with already existing models for transmission line, loads, 
wind turbine and others. Several cases of faults have been tested and analysed in order to show the robustness of the system.

Furthermore, some other research works investigate into the comparison of dynamic models for wind turbine. For instance, Múgica \& al. (2004), [8], developed six different models which were simulated under different degrees of complexity. Results show the adequacy of some models for dips voltage analysis, others for normal operation conditions. Akdag (2010), [9] uses wind data collected in Turkey to compare with different wind turbine models. Weibull distribution was used to determine the turbine energy outputs. Bharanikumar (2010), presents a maximum power point control for variable speed turbine driven permanent magnet generator [10]. In summary, his paper discusses the variable-speed wind energy conversion system using a permanent magnet generator and proposes the optimal control strategy of permanent magnet generator that helps to maximize the power generated.

Furthermore R. Melicio (2009), [11], developed a model of WTGS using a permanent magnet synchronous generator. The work aimed at improving the transient stability of the system by acting on the pitch angle. A new control strategy was proposed and simulated; simulation results show an improvement of system performances and robustness. In addition an analysis was carried out on the Total Harmonic Distortion (THD), which is a measure of system quality. Results show that the total THD was much lower than 5\% which is the limit imposed by IEEE-519 standard [12].

In summary, the above review of literature demonstrate that wind turbine modeling mostly goes with the use of doubly fed or squirrel cage induction generator and can be modeled and simulated under various conditions by two reputed software namely, DigSILENT and MATLAB. It was also found that, models of computation and validation of wind data, including Stochastic, Deterministic, Weibull and Exponential models were made available under MATLAB software.

\section{METHODOLOGY}

\subsection{Wind Turbine System Modeling}

The general scheme of a WTGS is depicted in figure 1

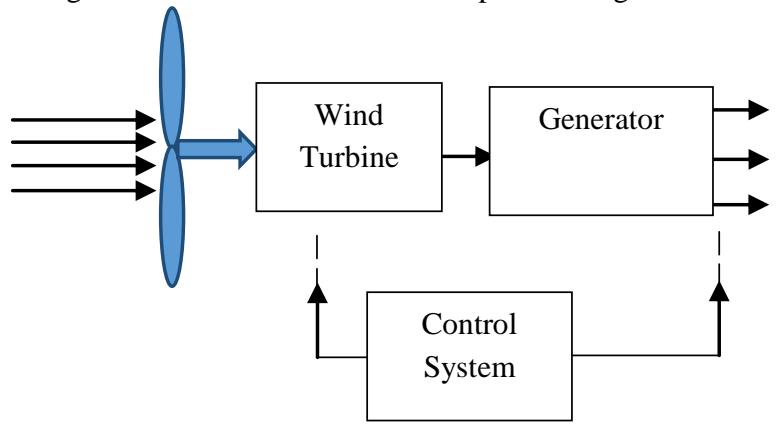

Fig 1: Bloc diagram of the WTGS

As described above, the process of wind energy generation, first involves the transformation of wind power into mechanical power by the use of wind turbine, followed by a transformation of the mechanical energy into electrical energy by the use of a generator. The wind energy produced by the WTGS is suggested to fluctuations of the wind speed that initially hit the turbine's blade. The proper conversion to electricity will therefore necessitate the use of controllable power converters mostly made of IGBTs. The existing problems of stability which is mainly due to the perturbations of input variables (wind speed, pitch angle, tip ratio), always force designers to consider some feedback control systems as illustrated in figure 1 , in order to achieve an effective production of energy.

Additionally, the type of turbine model used has a big influence on the modeling of the WTGS. [13] and [14] provided a comparative analysis on wind energy produced by variable speed wind turbine (VSWT) and fixe speed wind turbine (FSWT). Their findings show that the VSWT provides better energy capture over the fixe speed turbine because it can easily adapt itself to wide range of wind speed variation. For this reason the model considered in this paper is the VSWT one, coupled to a Doubly Fed Induction Generator (DFIG).

The methodology will first consist of handling the analytical modeling of the VSWT followed by its simulation with Matlab. Secondly, it will implement a graphical modeling and simulation of WTGS with pitch control under Matlab Simulink.

\subsection{Analytical Modeling}

The output power of a wind turbine generator system is usually given by equation $1,[15]$ and [16]:

$$
\mathrm{P}_{\mathrm{m}}=\frac{1}{2} \rho \mathrm{AC}_{\mathrm{p}} \mathrm{V}_{\mathrm{w}}^{3}
$$

Where:

- $\quad \mathrm{C}_{\mathrm{p}}$ is the coefficient of performance also called power coefficient

- $\quad$ A is the swept area by the turbine' blades $\left(\mathrm{m}^{2}\right)$

- $\quad \rho$ is the air density $\left(\mathrm{kg} / \mathrm{m}^{3}\right)$

- $\quad \mathrm{V}_{\mathrm{w}}$ is the wind speed $(\mathrm{m} / \mathrm{s})$

The coefficient $\mathrm{Cp}$ is not a constant [16]. It actually depends on two basic parameters namely: tip speed ratio, $\lambda$ and blade pitch angle $\beta$ (deg) [15]. With this consideration, equation 1 can be rewritten as

$$
P_{m}=\frac{1}{2} \pi \rho R^{2} C_{p}(\lambda, \beta) V_{w}^{3}
$$

The tip speed ratio $\lambda$ is defined as the ratio of the angular rotor speed of the wind turbine to the linear wind speed at the tip of the blades [16] and can be expressed as follow:

$$
\lambda=\frac{\omega_{\mathrm{r}} \mathrm{R}}{\mathrm{V}_{\mathrm{w}}}
$$

Where $\omega_{\mathrm{r}}$ is the mechanical angular velocity of the turbine rotor in $\mathrm{rad} / \mathrm{s}$ and $\mathrm{V}_{\mathrm{w}}$ is the wind speed in $\mathrm{m} / \mathrm{s}$ [16]. The rotational speed $\mathrm{n}(\mathrm{r} / \mathrm{min})$ and angular velocity $\omega_{\mathrm{r}}$ are related by equation 4 :

$$
\omega_{\mathrm{r}}=\frac{2 \pi \mathrm{n}}{60}
$$

According to [15] the driving torque around the rotor shaft can be given by the equation

$$
\mathrm{T}_{\mathrm{m}}=\frac{1}{2} \rho \mathrm{ARC}_{\mathrm{T}} \mathrm{V}_{\mathrm{w}}^{2}
$$

With $\mathrm{C}_{\mathrm{T}}$ the torque coefficient given by

$$
\mathrm{C}_{\mathrm{T}}=\frac{\mathrm{C}_{\mathrm{P}}}{\lambda}
$$


Based on [16], for a VSWT, the coefficient Cp is calculated as shown below.

$$
\lambda_{i}=\frac{1}{\frac{1}{\lambda+0.02 \beta}-\frac{0.03}{\beta^{3}+1}}
$$

With $\lambda$ as given by equation 2 .

$$
C_{p}(\lambda, \beta)=0.73\left[\frac{151}{\lambda_{i}}-0.58 \beta-0.002 \beta^{2.14}-13.2\right] e^{-\frac{18.4}{\lambda_{i}}}
$$

The code below written under Matlab simulation software help to plot the characteristic of $\mathrm{Cp}$ as well as the power generated in figure 2 and 3 respectively.

\section{$\%$ Wind turbine}

$\%$ Definition of parameters

$\%$ rotational speed $\mathrm{m} / \mathrm{s}$

$\%$ beta is the pitch angle

$\%$ lambda is the tip ratio

$\%$ Input parameters: $n, r, v w$, beta, ro

$n=700$

$r=1$;

$v w=[10: 0.001: 100]$;

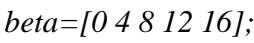

$r o=1$;

\%End Inputs

for $k=1: 5$

$$
w r=2 * p i * n / 60 ;
$$

lambda $=r^{*} w r . / v w$

$\%$ Calculation of lambda_k

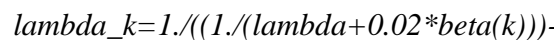
$\left.\left(0.03 /\left((\operatorname{beta}(k))^{\wedge} 3+1\right)\right)\right)$;

\section{$\%$ Calculation of power coefficient $c p$}

$c p=0.73 *(151 . /$ lambda $k-0.58 *$ beta $(k)$ $\left.0.02 *(\operatorname{beta}(k))^{\wedge} 2.14-13.2\right) . * \exp \left(-18.4 . / l a m b d a \_k\right)$;

\section{$\%$ Calculation of power \\ $p=0.5 * p i * r o * r^{\wedge} 2 . * c p . * v w . \wedge 3 ;$}

\section{$\%$ Result}

\section{figure (1)}

$\operatorname{plot}(v w, p)$, grid on, hold on,

\section{figure (2)}

plot(lambda,cp), grid on, hold on,

$C p$

end

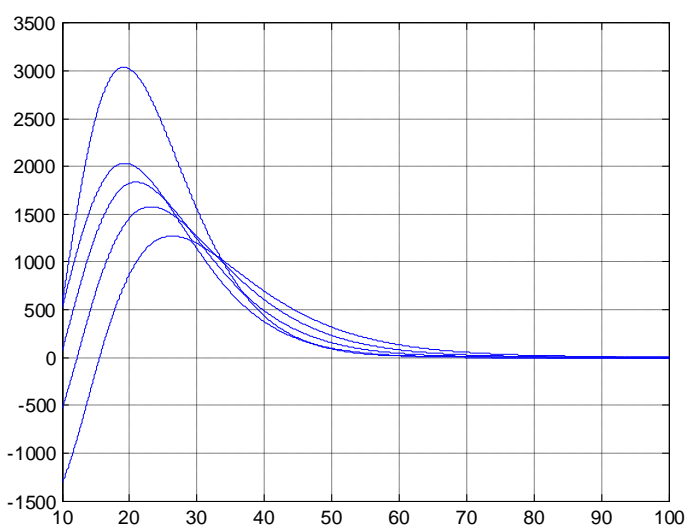

Fig 2: Turbine's output power versus wind speed for varying pitch angles

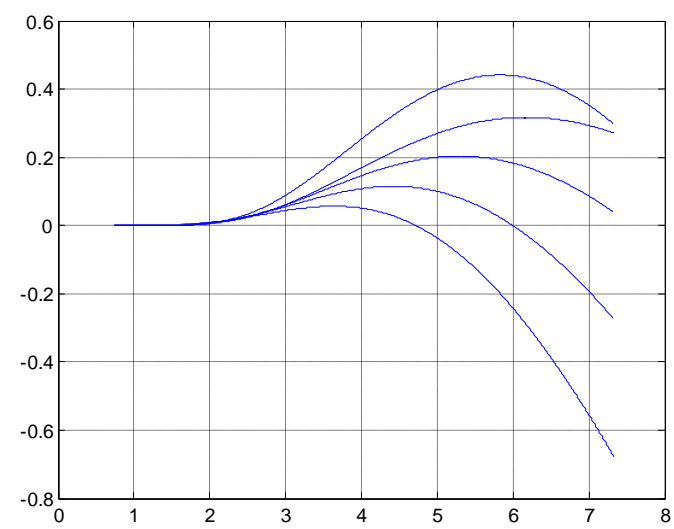

Fig 3: Power coefficient of the Turbine versus tip ratio for varying pitch angles

\subsection{Wind farm simulation using DFIG}

The adopted model of wind Turbine is an existing one under Matlab/Simulink. This model is depicted in figure 4 below and originated from [17], [18] and [19].

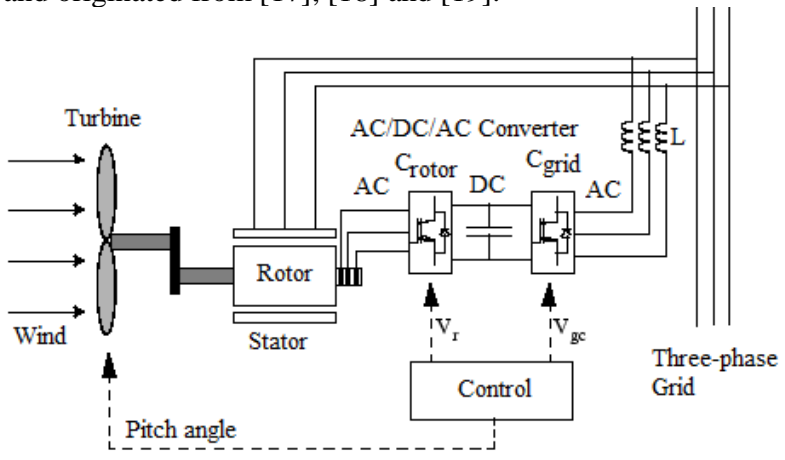

Fig 4: Adopted Model of WTGS under Matlab SimPowerSystem [17]

The model consists of a normal wind turbine whose analytical model was presented above. The rotor and stator of the induction generator are separated and clearly shown in figure4. Whilst the turbine shaft drives the rotor shaft through mechanical coupling, the stator is directly connected to the grid [18]. The power captured by the wind turbine is 
converted into electrical power by the induction generator and is transmitted to the grid through the stator winding.

The model also comprises an AC/DC/AC converter made of IGBT which helps in decoupling the electrical frequency and the mechanical rotor speed with the purpose of achieving variable speed operation. Slootweg \& al., [17], proves that the in-built control system generates the pitch angle command and some command voltage signals $\mathrm{Vr}$ and $\mathrm{Vgc}$ in order to control the power of the wind turbine, the DC bus voltage and the reactive power or the voltage at the grid terminals. This model of Wind Turbine, DFIG, is used to simulate the WTGS system.

Nevertheless, the speed of the rotor and power generated can be evaluated by considering the dynamic aspect of the system. The mechanical power as well as the stator electric power output can be evaluated as follow:

$$
\begin{aligned}
& P_{m}=T_{m} \cdot \omega_{r} \\
& P_{S}=T_{e m} \cdot \omega_{S}
\end{aligned}
$$

For a lossless generator the mechanical equation is:

$$
\mathrm{J} \frac{\mathrm{d}\left(\omega_{\mathrm{r}}\right)}{\mathrm{dt}}=\mathrm{T}_{\mathrm{m}}-\mathrm{T}_{\mathrm{em}}
$$

Again for a lossless generator, in steady state, $\mathrm{Tm}=\mathrm{Tem}$ and $\mathrm{Pm}=\mathrm{Ps}+\mathrm{Pr}$. It follows that:

$$
\mathrm{P}_{\mathrm{r}}=\mathrm{P}_{\mathrm{m}}-\mathrm{P}_{\mathrm{S}}=\mathrm{T}_{\mathrm{m}} \cdot \omega_{\mathrm{r}}-\mathrm{T}_{\mathrm{em}} \cdot \omega_{\mathrm{S}}=-\mathrm{T}_{\mathrm{m}} \frac{\omega_{\mathrm{S}}-\omega_{\mathrm{r}}}{\omega_{\mathrm{S}}} \cdot \omega_{\mathrm{S}}
$$

For s the slip ring defined as follow:

$$
\mathrm{s}=\frac{\omega_{\mathrm{S}}-\omega_{\mathrm{r}}}{\omega_{\mathrm{S}}}
$$

Pr can finally be inferred as:

$$
\mathrm{P}_{\mathrm{r}}=-\mathrm{sT}_{\mathrm{m}} \omega_{\mathrm{s}}=-\mathrm{s} \mathrm{P}_{\mathrm{m}}
$$

The network model is shown in figure 5. It consists of a 6 MW wind turbine generator made of six $1 \mathrm{MW}$ wind turbines. The generated power is connected to a $33 \mathrm{kV}$ distribution system that transports the power to a load through a $20 \mathrm{~km}, 33$ $\mathrm{kV}$ feeder. The wind turbine adopted, comprises the four basic elements described above, namely the turbine itself, DFIG, the $\mathrm{AC} / \mathrm{DC} / \mathrm{AC}$ converter and the control system.

A PID controller existing under the adopted model of wind turbine has been used to control the rotor speed. Such controller is designed to make stable the rotor speed irrespective of the variations of the wind speed and this is achieved by adjusting the pitch angle. Figure 6 depicts the operation of the controller where $\Delta \omega_{\mathrm{r}}$ represents the variations in the rotor speed and $\Delta \mathrm{Uc}$ represents the changes in the output pitch angle.

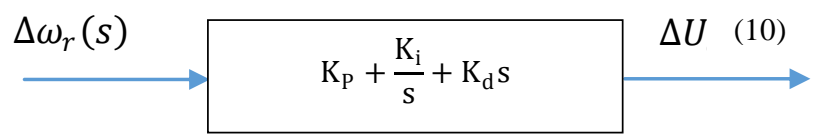

Fig 6: Bloc diagram of the PID control system

The transfer function between the output pitch angle and the variation in rotor speed is given by

$$
\mathrm{G}(\mathrm{s})=\frac{\Delta \mathrm{U}_{\mathrm{c}}(\mathrm{s})}{\Delta \omega_{\mathrm{r}}(\mathrm{s})}=\mathrm{K}_{\mathrm{P}}+\frac{\mathrm{K}_{\mathrm{i}}}{\mathrm{s}}+\mathrm{K}_{\mathrm{d}} \mathrm{s}
$$

This PID will be manually tuned until the optimum values leading to the best speed regulation will be obtained. The final values obtained will be discussed in the results.

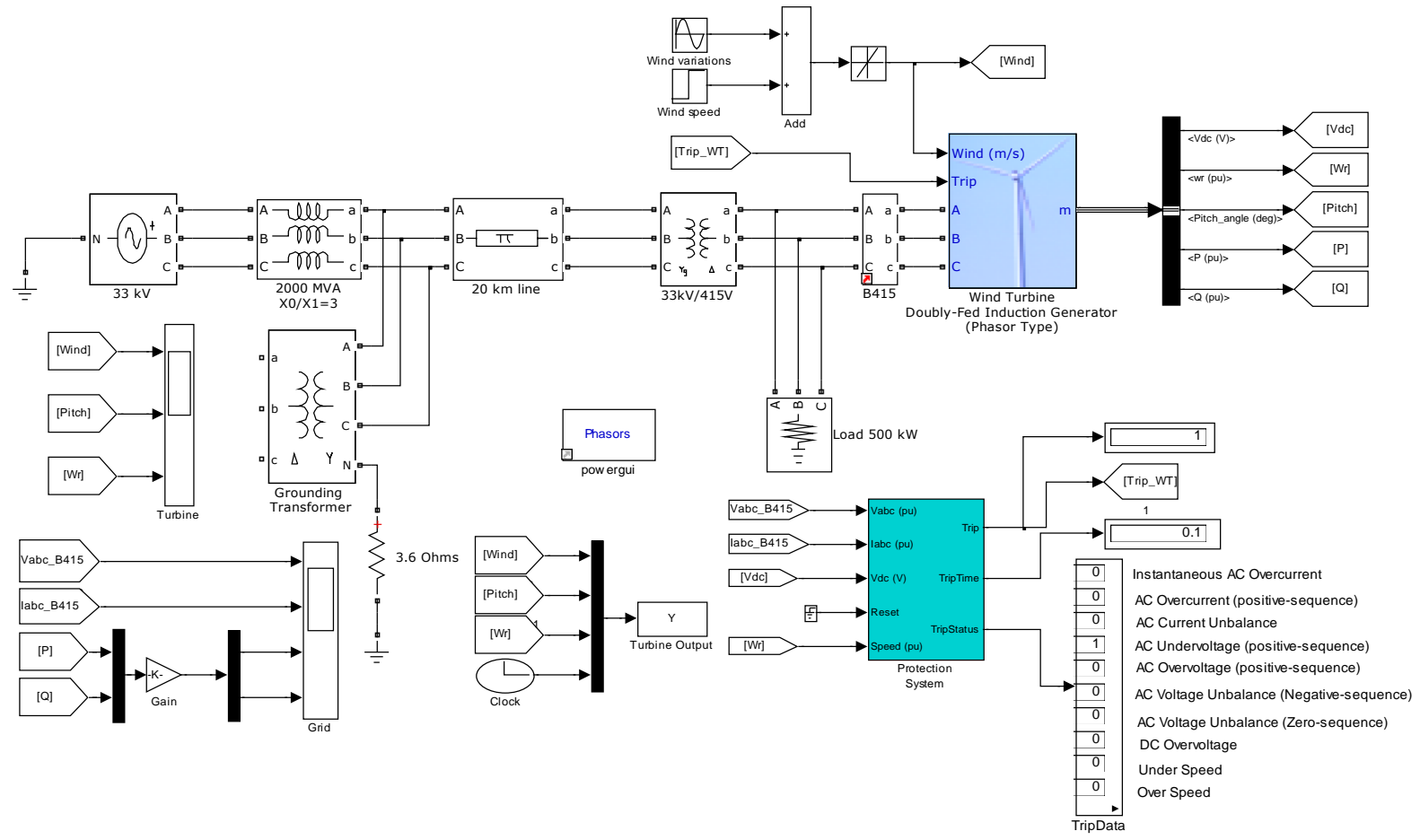

Fig 5: Simulated model of DFIG WTGS under Matlab/SimPowerSystem 


\section{RESULTS AND ANALYSIS}

The simulation results are shown in figure 7 and figure 8 respectively. Each parameter of the PID controller has been tuned manually in order to adapt the variation of the pitch angle to that of the wind speed with the objective to maintain the speed constant. The final values that give the best performances for the PID controller are as follow: $\mathbf{K}_{\mathbf{P}}=\mathbf{0 . 3}$ $\mathbf{K}_{\mathbf{I}}=\mathbf{8}$ and $\mathbf{K}_{\mathbf{D}}=0$. The three sub-figures of figure 7 show respectively, the wind speed, the pitch angle variation and the mechanical angular velocity at the output. The PID controller is set to start control after 5 second. From the beginning (time $=0$ ) to the preset five second, there was a strong variation in the rotor speed as a result of wind speed variation. This is normal due to the non-activation of the feedback control system. After five second when the controller has started work, the regulation of speed was not immediately remarkable due to a big change in wind speed (averagely 8 to $13 \mathrm{~m} / \mathrm{s}$ ) within the interval of 10 to $20 \mathrm{~m} / \mathrm{s}$. This is illustrated on the graph by a rise in wind speed within the interval of 10 to 20 second. Subsequently, an automatic rise in the pitch angle as well as the rotor speed followed. Afterward, despite the continuous variation in wind speed, the rotor speed was perfectly regulated. The graph on the pitch angle shows how the controller, dynamically allocated pitch angle value to overcome the speed variation. After 50s, the speed become almost constant even though the wind speed keeps oscillating within the range of 12 to $15 \mathrm{~m} / \mathrm{s}$.

Furthermore, figure 8 also shows the voltage and current generated as well as the active and reactive power generated. The first two sub-figures of figure 8 shows respectively the voltage and current generated. The active power exhibits some strong oscillations within the range of -6 to -2 pu. Only the reactive power was constantly zero due to the absence inductive load (the load was purely resistive). After five second when the control started, the voltage, current and active power stabilized respectively to their steady-state values of $0.5 \mathrm{pu}$ and $1 \mathrm{pu}$ and $-0.5 \mathrm{pu}$. This stability confirms the effectiveness of the entire control system ranging from the PID to the AC/DC/AC converters made of IGBTs.
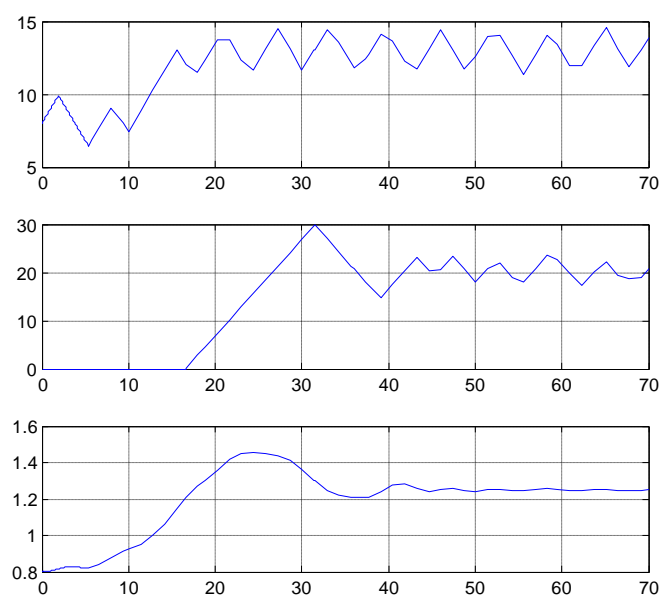

Fig 7: Simulation results on the turbine speed variations

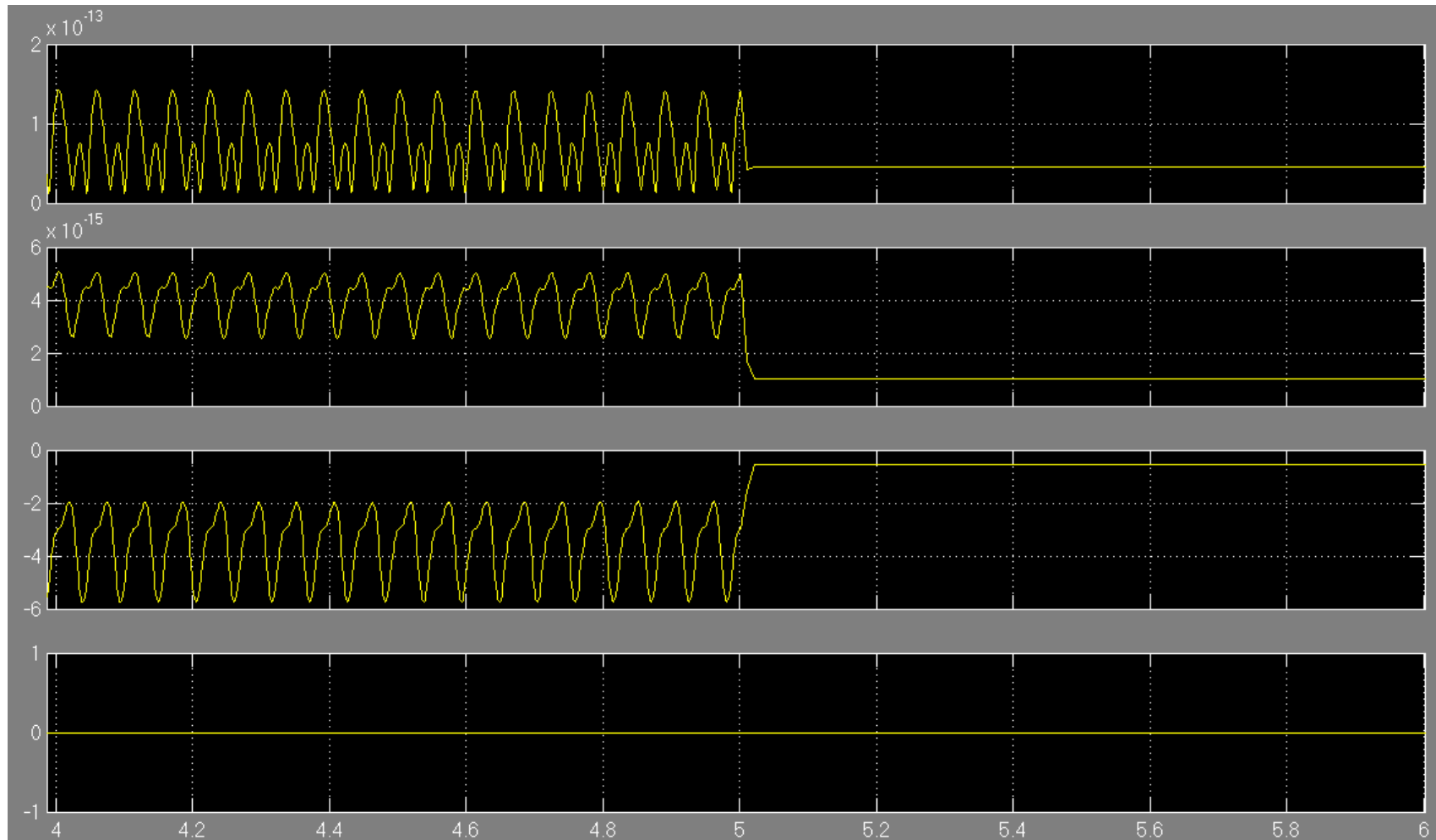

Fig 8: Simulation results on grid parameters 


\section{CONCLUSION}

In summary, this paper presented the modeling and simulation of a variable speed wind turbine using DFIG under Matlab/SimPowerSystem. Firstly an analytical model of wind turbine was presented and power coefficient characteristics were investigated. Furthermore, a graphical model of $6 \mathrm{MW}$ wind farm was built with enhanced control of speed using PID controller. At first when the control system was not applied, the rotor speed was very unstable but after $5 \mathrm{~s}$ and also due to a perfect tuning of the PID controller, results were very prominent in terms of stability of the rotor speed vis-à-vis the wind variation. The rotor speed was merely constant after $50 \mathrm{~s}$ despite the wind speed was still varying within the range of $12 \mathrm{~m} / \mathrm{s}$ to $15 \mathrm{~m} / \mathrm{s}$. On the other hand, the voltage generated as well as the reactive and active power were also good. This model of wind turbine can later serve to build hybrid energy supply in combination with other renewable energies that could also be modeled using the same software.

\section{REFERENCES}

[1] Manwell, F. J., McGowan J. G., and Rogers A. 2002. Wind Energy Explained. John Wiley \& Sons, New York.

[2] Omar, N. 2011. Low Voltage Ride through Strategies for SCIG Wind Turbines Interconnected Grid. International Journal of Electrical \& Computer Sciences, IJECSIJENS, Vol.11, No.02, pp. 53-58.

[3] Hansen, A. D., Jauch, C., Sørensen, P., Iov, F., and Blaabjerg, F. 2003. Dynamic Wind Turbine Models in Power System Simulation tool DigSILENT. Ris $\varnothing-$ National Laboratory, Roskidle.

[4] Bolik, S. 2003. Grid Requirements challenges for Wind Turbines. Billund: Fourth International workshop on Large-Scale Integration of Wind Power and Transmission Networks for Offshore Wind farms.

[5] Fingersh, L., Hand, M., and Laxson, A. 2006. Wind Turbine Design Cost and Scaling Model. National Renewable Energy Laboratory, U.S. Department of Energy: technical Report, NREL/TP-500-40566.

[6] Petru, T. 2001. Modeling of Wind Turbine for Power System Studies. Goteborg-Sweden: Department of Electric Power Engineering, Chalmers University of technology

[7] Sulla, F. 2009. Simulation of DFIG and FSIG with Farms in MATLAB SimPowerSystems. Lund University: Division of Industrial Electrical Engineering and Automation. LUTEDX/(TEIE-7235)/1-007.

[8] Múgica, M. S., Urkiola, A. M., Vidal, M. R., and Redondo, R. R. 2004. Comparison Of Dynamic Models For Wind Turbine Grid Integration Studies. Portugal.
[9] Akdag, S. A., and Güler, O. 2010. Comparison of Wind Turbine Power Curve Models. Sousse, Tunisia: International Renewable Energy Congress.

[10] Bharanikumar, R., Yazhini, A. C., and Kumar, A. N. 2010. Modeling and Simulation of Wind Turbine Driven Permanent Magnet Generator with New MPPT Algorithm. Asian Power Electronics Journal, Vol. 4 No.2.

[11] Melício, R., Mendes, V. M. F., and Catalão, J. P. S. 2009. Computer Simulation of Wind Power Systems: Power Electronics and Transient Stability Analysis. Kyoto, Japan: International Conference on Power Systems Transients (IPST2009).

[12] Duffey, C.K. 1988. Update of harmonic standard IEEE519: IEEE Recommended Practices and Requirements for Harmonic Control in Electric Power Systems. In proc of IEEE: Petroleum and Chemical Industry Conference, pp. 249-255.

[13] Akhmatov, V. 2002. Variable-Speed Wind Turbines with Doubly-Fed Induction Generators, Part I: Modelling in Dynamic Simulation Tools. Wind Engineering Vol. 26, No. 2.

[14] Siano, P. 2007. Design and implementation of a fuzzy controller for wind generators performance optimisation European Conference on Power Electronics and Applications, In proc. IEEE Power Electronics and Applications, European Conference, pp. 1-10.

[15] Abbas, F. A. R., and Abdulsada, M. A. 2010. Simulation of Wind-Turbine Speed Control by MATLAB. International Journal of Computer and Electrical Engineering. Vol. 2, No. 5, 1793-8163p.

[16] Khajuria, S., and Kaur, J. 2012. Implementation of Pitch Control of Wind Turbine using Simulink (Matlab). International Journal of Advanced Research in computer Engineering and technology (IJARCET), voll, ISSN: 2278-1323.

[17] Slootweg, J.G., de Haan, S.W.H., Polinder, H., and Kling, W.L. 2003. General model for representing variable speed wind turbines in power system dynamics simulations. IEEE Transactions on Power Systems, Vol.18, No.1, pp.144-151

[18] Iov, F., Hansen, A. D., Sørensen, P., and Blaabjerg, F. 2004. Wind Turbine Blockset in Matlab/Simulink. Denmark: Aalborg University.

[19] Pena, R., Clare, J.C., and Asher, G.M. 1996. Doubly fed induction generator using back-to-back PWM converters and its application to variable-speed wind-energy generation. IEEE Proc.-Electr. Power Appl., Vol. 143, No. 3 . 